\title{
DONA MARCOLINA, UMA MEGERA INDOMADA: REPRESENTACÕES E ESTEREÓTIPOS DE FEMINILIDADE NOS QUADRINHOS DE ALCEU CHICHÔRRO
}

\author{
DONA MARCOLINA, AN UNTAMED SHREW: REPRESENTATIONS AND STEREOTYPES OF FEMININITY IN THE \\ COMICS OF ALCEU CHICHÔRRO
}

\section{RESUMO}

Neste artigo, pretendemos refletir sobre a personagem Dona Marcolina, criada pelo jornalista e chargista Alceu Chichôrro (1896-1977), publicada no jornal curitibano $O$ Dia, no período de 1926 a 1961. Na companhia de Chico Fumaça e do cachorro Totó, Dona Marcolina representa um tipo de feminilidade associado às mulheres, constituído de camadas de discursos normatizantes e hierarquizantes, com traços físicos caricatos, como também modos exagerados de agir, pensar e reagir a determinadas práticas sociais masculinas, ironizando os espaços de domínio das mulheres e questionando quem, de fato, deveria mandar na casa. Dentro da tradição do humor gráfico e das chamadas family strips do início do século XX, destacam-se personagens femininas - caracterizadas por serem tiranas, mandonas, mal-humoradas e fora dos padrões de beleza da época - que geralmente são descritas como feias. Além disso, são desenhadas altas, magras, em contraponto a seus pares, homens baixinhos e gordos. Estes contrastes e desproporções provocam o efeito cômico, evocando a comédia popular, e reiteram a inversão de papéis sociais esperados pela sociedade. Estas personagens mandam, controlam e batem nos homens. O pau/rolo de macarrão torna-se um artefato comum no desfecho das charges e tiras cômicas, usado no último quadrinho para golpear e punir os deslizes, travessuras dos homens.

Palavras-chave: Representações. Estereótipos. Gênero. Tiras cômicas. Dona Marcolina. Alceu Chichôrro.

\begin{abstract}
In this article, we intend to reflect on the character of Dona Marcolina, created by the journalist and cartoonist Alceu Chichôrro (1896-1977), published in the newspaper O Dia, from 1926 to 1961. In the company of Chico Fumaça and the dog Totó, Dona Marcolina represents a type of femininity associated with women, composed of normative and hierarchical discourses, with caricatural physical traits, as well as exaggerated ways of acting, thinking and reacting to certain masculine social practices, ironically looking upon spaces of female domain and questioning who, in fact, should be in charge in the house. Within the tradition of graphic humor and the so-called family strips of the early twentieth century, female characters characterized by being tyrannical, bossy, moody, and non-conforming to beauty

Thaís Mannala

Universidade Tecnológica Federal do Paraná (UTFPR) - Brasil. E-mail: thais.mannala@gmail.com Marilda L. P. Queluz

Universidade Tecnológica Federal do Paraná (UTFPR) - Brasil. E-mail: pqueluz@gmail.com
\end{abstract}


standards of the period - stand out and are often described as ugly. Furthermore, they are drawn tall, thin, in counterpoint to their partners, small and fat men. These contrasts and disproportions provoke the comic effect, evoking popular comedy, and reiterate the reversal of social roles expected by society. These characters command, control and beat the men. The stick/pasta roll becomes a common artifact at the end of the strips, used in the last panel to strike and punish the mistakes, mischief of men.

Keywords: Representations. Stereotypes. Gender. Comic strips. Dona Marcolina. Alceu Chichôrro.

\section{CONTEXTO}

As charges, os quadrinhos e as tiras cômicas são pensados aqui como umartefato cultural, como um "espaço de recepção e interação" que veiculam "representações sobre as mulheres, os homens, a sociedade” (Swain, 2001: 14). São nestes espaços que modelos e valores determinam "suas aptidões e possibilidades, e criam paradigmas físicos, morais, mentais cujas associações tendem a homogeneizar o 'ser mulher', desenhando em múltiplos registros o perfil da 'verdadeira mulher'. (Swain, 2001: 12). As representações humorísticas, muitas vezes, constroem ou reforçam estereótipos, em conivência com os sistemas de controle e opressão, definindo papéis sociais e posições de sujeitos, estabelecendo hierarquias e relações de poder (Swain, 2000). Esses sistemas são "postos ao trabalho" postos ao trabalho, por certas tecnologias e estratégias de aplicação, em situações específicas, contextos históricos e regimes institucionais" (Hall, 2016: 89).

Por outro lado, a linguagem do humor gráfico opera no sentido de questionar, ironizarou contrapor representações, regimes de verdade nos quais corpos e comportamentos são disciplinados. Nesta perspectiva, usamos o conceito de representação proposto por Roger Chartier (1988), entendido como uma arena de disputas, tensionada por estratégias empreendidas por grupo(s) de interesse, em um jogo de dominação e poder. Nas práticas dinâmicas e intercambiantes de leitura, no campo social onde circula o conjunto de textos, ideias e normas culturais, a realidade é construída de forma contraditória por distintas esferas da sociedade. A prática de leitura e de criação são atos que requerem um processo de construção de sentido por parte do leitor/autor que ao ler/construir uma imagem ou um texto atribuem significados. São modos de ver e pensar o real como um discurso legítimo, segundo experiências e repertórios compartilhados como sujeito receptor ou emissor. Nas caricaturas e tiras cômicas ocorre uma via de mão dupla paradoxal: enquanto valores são colocados de forma crítica para relativização das normas sociais, também acabam por reforçar padrões hegemônicos. Neste aspecto, as representações são práticas sociais que carregam os valores, as imposições e as concepções sobre a sociedade, nos quais alguns grupos são legitimados e outros invisibilizados, excluídos. 
O humor gráfico como expressão visual dos tipos populares e suas representações teve sua difusão associada às novas técnicas gráficas de impressão no final do século XIX e início do século XX. Em conjunto, elas ajudaram a elaborar novas formas de ver e estar no mundo, diferentes regimes de visualidade. Este aumento do consumo e circulação de imagens, ligado ao aprimoramento da imprensa diária, é forjado junto às transformações sociais, às reformas urbanas, às mudanças de comportamento, às novas posições de sujeito marcadas pelo crescimento das cidades e pela industrialização. Multiplicam-se as revistas ilustradas, as revistas de humor e, além das charges, os jornais passam a publicar tiras cômicas com narrativas visuais do cotidiano, satirizando, reproduzindo ou questionando os hábitos, costumes, valores da sociedade, deixando entrever as contradições e as relações de poder. Os efeitos da política ou da economia, como a alta dos preços, ou as disputas simbólicas, envolvendo as relações assimétricas de poder entre homens e mulheres, as diferenças de classe, raça e etnia passam a fazer parte das temáticas dos quadrinhos, especialmente um gênero conhecido como family strips.

O objetivo deste texto é refletir sobre Dona Marcolina, uma personagem feminina que faz parte de uma longa tradição de se representar mulheres fortes, decididas, rabugentas e indomáveis'. Sua família é composta por Chico Fumaça e o cachorrinho Totó e habita o universo dos desenhos de Alceu Chichôrro (1896-1977), sob o pseudônimo de Eloy, publicadas no jornal O Dia (1923-1961)².

Chichôrro nasceu em Curitiba, foi jornalista, funcionário público, cronista e chargista, e atuou em jornais locais, como A Tribuna, O Comércio do Paraná, Gazeta do Povo. Também fundou periódicos como o humorístico O Anzol, Jazz e Máscara (Bahls \& Buso, 2009). Suas charges e tiras cômicas propunham uma opinião crítica sobre o cotidiano da cidade, os problemas urbanos, os comportamentos sociais, os caminhos da política nacional. Embora se opusesse a qualquer tipo de censura e opressão, principalmente durante a era Vargas, suas representações de feminilidades e masculinidades não desafiavam ou problematizavam os padrões hegemônicos.

Dentre os muitos personagens criados por Chichôrro, o que mais ganhou aceitação popular, confundindo-se inclusive com seu criador (Bahls \& Buso, 2009: 168), foi o calunga ${ }^{3}$ Chico Fumaça. Wilson Boia (1998), descreve Fumaça como:

\footnotetext{
1 A figura da mulher dominadora, mandona e que bate no marido é um clichê muito popular, com várias raízes na literatura e no teatro. Marcela Gené (2012) aponta como a questão da autoridade feminina já amedrontava os homens da Idade Média e do Renascimento, podendo ser encontrada nas obras de Chaucer ao teatro isabelino, de Rabelais ao teatro e às narrativas francesas dos séculos XVII e XVIII. Uma referência importante é a famosa comédia de Shakespeare, A Megera Domada, com a presença de Catarina.

2 O levantamento dos jornais foi feito no acervo da Hemeroteca da Biblioteca Nacional, <http:// bndigital.bn.gov.br/acervodigital>.

3 Calunga era a denominação dada aos bonecos, silhuetas e desenhos publicados nas revistas de humor, talvez como influência da cultura afrobrasileira para denominar as imagens de entidades da umbanda. Os personagens de Alceu Chichôrro eram apelidados de calungas (Bahls \& Buso, 2009). Dentre os principais, destacam-se: Tancredo (11 meses de existência) e Minervino (53 dias de existência) (Boia, 1994; 1998). Segundo o dicionário Houaiss (2009), calunga é um termo regional, a saber: "boneco, espécie de pequeno tamanho"; "indivíduo de baixa estatura”. Tal definição combina com a descrição dos
} 
Tipo gorducho, baixinho e barrigudo. Cara redonda. Nariz redondo, olhos semicerrados. Sobrancelhas altas e ralas. Boca rasgada. Bigode preto, espesso, retangular, quase engolindo a boca. Na careca, três fios de cabelo ente duas orelhas. Bunda empinada.

$[\ldots]$

Solteirão convicto. "Enquanto não houver lei de divórcio, o Fumaça ficará peromnia secula seculorum, solteiro e completamente divorciado das ideias matrimoniais" (Boia, 1998: 40-41).

A imagem de um solteirão era reforçada como algo positivo, como sinônimo de liberdade, levando uma vida boêmia, de festas regadas por muita bebida e cercado por muitas mulheres bonitas e sensuais. Chico Fumaça morava com sua tia, Dona Marcolina, personagem marcado por uma certa ambiguidade, pois, muitas vezes, agia como uma esposa opressora. Essa fluidez de comportamento a coloca entre a tia solteirona rabugenta, a mulher ciumenta e controladora, aquela que manda na casa. Boia (1998: 41) a intitula como tia e tutora de Chico Fumaça, algo que, na prática, refletia-se nas "violentas pancadas com um rolo de macarrão ou com uma vassoura" deferidas no personagem. Para o pesquisador, Dona Marcolina (ver Figura 1) é:

Maior de cinquenta anos de idade [...]

Alta, seca, magra, nariguda, tipo longilíneo, orelhas em abano, prognata ${ }^{4}$, cara comprida, feições grosseiras, com dois dentes, cabelo enrolado em forma de coque com dois pega-rapazes, vestido comprido com barra de listras verticais, sapato preto de salto alto, empunhando de quando em quando uma vassoura ou um rolo de macarrão, suas poderosas armas de ataque contra as artimanhas do Chico Fumaça (Boia, 1998: 41).

Na descrição de Wilson Boia (1998) está implícita a ideia de atributos negativos associados à idade e ao fato de não ter constituído sua própria família. Dona Marcolina é a representação de um tipo de feminilidade associado ao que se esperava de uma solteirona, aquela que "ficou para titia". É considerada feia, desajeitada, com roupas e penteado fora de moda, amargurada pelo tempo, demonstrando agressividade em muitas situações.

personagens, de estatura baixa, lembrando pequenos bonecos, sendo o Chico Fumaça, neste aspecto, é o que melhor se encaixa.

4 Pessoa que apresenta o maxilar inferior proeminente (Houaiss, 2009). 
Figura 1: O Dia, o9 ago. 1942, capa.

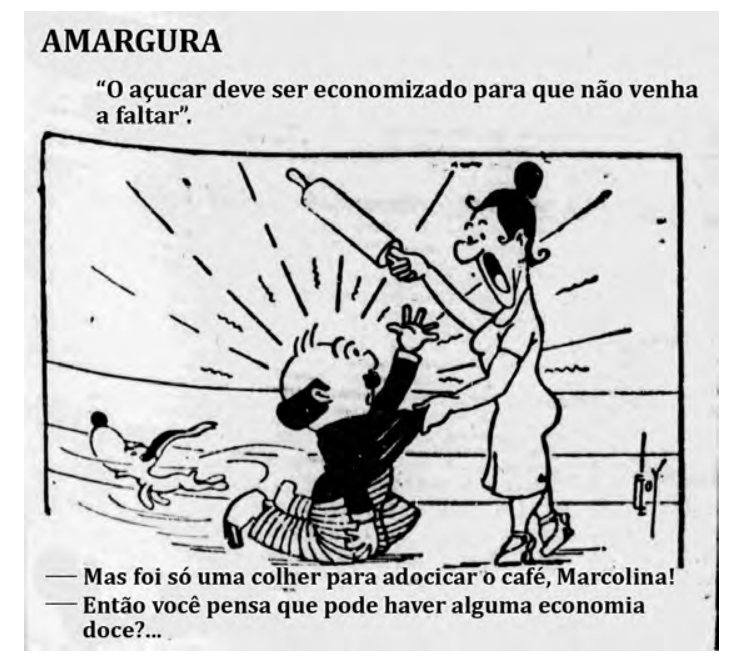

Fonte: Hemeroteca da Biblioteca Nacional.

Essa amargura é mostrada na Figura 1, na qual pode-se observar como Chichôrro conjuga os problemas econômicos e a escassez de alguns alimentos durante o período da segunda guerra mundial e a rigorosa administração do lar feita por Marcolina. A cena de Chico Fumaça ajoelhado, pedindo clemência à mulher para não apanhar com o pau de macarrão, acabou por se tornar uma cena emblemática nos quadrinhos de Chichôrro.

Fisicamente, D. Marcolina contrastava com um ideal de beleza vigente difundido pelas revistas ilustradas, a saber: jovem, ativa, de feições suaves e saudáveis, sensual, moderna. Simbolicamente, traçava-se em seu corpo a carga esperada de comportamentos que uma mulher de classe média, solteira, na faixa dos cinquenta anos deveria possuir, como a amargura externalizada por meio de agressões físicas à figura masculina, o controle moral e administrativo do lar. O efeito cômico advinha da suposta inversão de papéis, em que o domínio e a violência por parte da personagem a ridicularizavam, evocando o absurdo da cena e devolvendo a razão ao "pobre" coitado, vítima da tirania feminina. Tais características fazem parte de um estereótipo corrente durante as primeiras décadas do século XX. Para traçar a personalidade de D. Marcolina, é necessário entender as influências, diálogos, diferenças e proximidades dela em relação a outras personagens que circulavam pelo Brasil e pelo mundo, perdurando e sendo atualizadas por um longo período.

As histórias de Chico Fumaça (primeira aparição em 23 de maio de 1926) e de D. Marcolina (primeira aparição em 15 de junho de 1927) foram publicadas no jornal O Dia durante o período de 1926 a 1961 e republicadas duas vezes por semana na Gazeta do Povo e no relançamento do novo jornal O Dia, na década de 1970. Esses personagens possuíam não somente traços físicos caricatos como também modos exagerados de agir, pensar e reagir sobre as práticas sociais. As influências e os estereótipos que compõem Dona Marcolina, tia e tutora de Chico Fumaça, revelam 
representações de uma feminilidade negativada pela sociedade da época, ao mesmo tempo que elas dialogam com a história do humor gráfico das family strips.

\section{FAMILY STRIPS, ESTEREÓTIPOS E GÊNERO: MASCARANDO A DESIGUALDADE}

A family stripfoi um gênero de quadrinho muito difundido no início do século $\mathrm{XX}$, caracterizado principalmente por assuntos do cotidiano familiar, em geral, associadas a valores urbanos e comportamentais burgueses (Oliveira, 2007; Maluf \& Mott, 1998). Apesar da sua popularização no começo do século XX com os Syndicates ${ }^{5}$, essa categoria já se fazia presente em outros países, seja na forma de charges e tiras cômicas, seja através da abordagem familiar na literatura, por exemplo.

Waldomiro Vergueiro (2003) afirma que, pelo seu caráter universal, as tiras com temas familiares foram de fácil assimilação pelos leitores e uma estratégia comercial dos produtores de tiras diárias que investiram em:

[...] uma forma bem-humorada e muitas vezes até mesmo inocente, o dia-a-dia do norte-americano comum, com suas dificuldades, alegrias, tristezas, sonhos e desilusões, imaginando que esta forma de pintar a realidade poderia ser facilmente transplantada para outras sociedades. A fórmula atingiu o objetivo esperado e em pouco tempo os jornais norte-americanos se viram abarrotados de quadrinhos que retratavam o american way of life das mais variadas formas e ajudavam a divulgar os costumes e valores norte-americanos pelo mundo inteiro, com todas as implicações ideológicas que esse fato representava (Vergueiro, 2003, on-line).

O que se percebe, entretanto, é que, embora seguindo uma fórmula básica, um clichê, muitos elementos regionais e valores culturais específicos são adicionados, sendo as desavenças familiares, matrimoniais e os problemas cotidianos ressignificados de acordo com o contexto local em que essas histórias eram veiculadas.

É interessante observar a opinião de Vergueiro sobre as personagens femininas:

De uma certa forma, as mulheres já tinham uma função proeminente nas chamadas family strips, em que concentravam as rédeas do poder e muitas vezes determinavam a maioria dos acontecimentos, como acontece em grande parte das famílias. Ao refletir a família norte-americana, essas tiras em quadrinhos freqüentemente colocavam a mulher em papel de destaque em relação ao homem, que muitas vezes ficava relegado ao papel de pagador das contas, humilde cumpridor de ordens ou títere indefeso frente às decisões da matrona do lar (Vergueiro, 2003).

5 Os Syndicates norte-americanos foram empresas de "exportação de narrativas quadrinizadas" (Vergueiro, 2003, on-line), com a venda dos direitos de publicação de charges, tiras cômicas ou quadrinhos. 
O exemplo mais famoso deste gênero é o casal criado em 1913 por George McManus $^{6}$ (1884-1954), Pafúncio e Marocas (Maggie e Jiggs ou Bringing up Father), "casal irlandês-americano que, após ser sorteado com o primeiro prêmio de um bilhete de loteria, se viu elevado à condição de novo rico" (Oliveira, 2007: 45).

O casamento, para Pafúncio, é percebido como algo que agrega apenas status social, mas nenhum prazer. Este se encontrava nas ruas, nos bares, nas festas, no trabalho e nas escapadelas com sua secretária. "Embora Marocas fosse o símbolo da esposa-megera, McManus divertia-se desenhando belas jovens para tentar o velho Jiggs" (Goidanich \& Kleinert, 2011). Para Selma Oliveira (2007), o casamento traz alguns direitos a Marocas, dentre eles o de "atormentar e castrar seu marido, subordinando-o a seus caprichos" (Oliveira, 2007: 48).

Marcela Gené (2012: 206) chama a atenção para o gesto recorrente de brandir o rolo de macarrão como um símbolo da esposa tirana/megera: "Poucas coisas parecem ter identificado o poder feminino com tanta precisão quanto este utensílio, que mudou seu significado como atributo de uma dona de casa habilidosa para a arma letal de maridos indisciplinados" ${ }^{\text {. }}$

Figura 2. Capa da revistaJiggsandMaggie n.23, 1949.

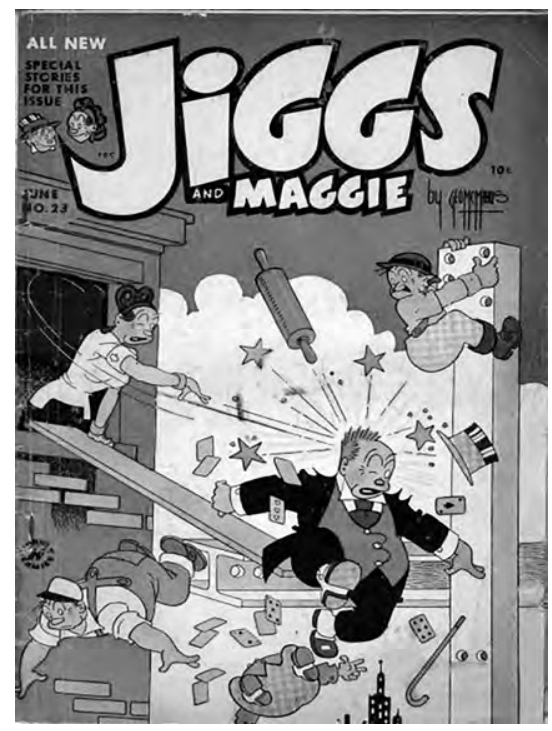

Fonte: https://goo.gl/YhtYx8

6 George McManus nasceu de pais irlandeses em St. Louis, Estados Unidos. Publicou sua primeira tira em 1904 em um jornal local. Porém, foi quando se mudou para Nova York onde ganhou espaço e, em 1913, criou Bringing Up Father, conhecido internacionalmente."Com seu humor sutil, mas implacável, ele descreveu a sociedade americana, ridicularizando seu desejo insaciável de luxo e seu egoísmo", influenciando toda uma geração (LAMBIEK, 2014, on-line).

7 Na capa da edição de O Dia de o6 de nov. 1931, a charge de Alceu Chichorro divide espaço com uma tira cômica de George McManus podendo ser acessada em: <https://goo.gl/AB5Vhm>.

8 Texto original "Pocas cosas parecen haber identificado con tanta precisión el poder femenino como este utensilio, que trocó su significado como atributo de un ama de casa hacendosa por el de arma letal para díscolos maridos". 
Este traço autoritário e dominante da esposa de Pafúncio está presente na figura da D. Marcolina. O semblante fechado e a eterna vigilância sobre a figura masculina, traz ideias relacionadas ao modelo ideal de casamento e de papéis sociais. Na visão das pesquisadoras Selma Oliveira (2007), Marina Maluf e Maria Lúcia Mott (1998), o casamento é visto como única instituição capaz de manter a ordem social, bem como promover e dignificar a mulher em seu papel como esposa, mãe e dona de casa.

Por mais que D. Marcolina fosse concebida por Alceu Chichôrro para ser tia de Chico Fumaça, suas ações são equivalentes às de uma esposa que pune e vigia os passos do homem para a manutenção da moral e os bons costumes. Um bom exemplo é o modo como ela reage aos novos hábitos de frequentar a praia, de buscar uma vida saudável e aproveitar os efeitos positivos do sol e dos banhos e atividades aquáticas (Figura 3). No segundo quadrinho, vemos três jovens exibindo trajes de banho modernos na época, penteados e cortes de cabelo seguindo as tendências do cinema, destoando fortemente da roupa inadequada e do visual recatado e antiquado de Marcolina. Chico Fumaça, ao tentar se exibir, acaba por piorar ainda mais a aparência da tia, molhando-a por completo, o que lhe rende uma pancada com o pau de macarrão. A maior parte dos outros tipos femininos representados por Chichorro são um contraponto a Marcolina, são jovens sorridentes, delicadas, modernas, vestidas de acordo com a moda, com corpos marcados por curvas sensuais, inclinadas a se envolver com o personagem de meia idade, baixinho e careca. Vale lembrar a ironia ao "tanque do Bacacheri", um bairro afastado da cidade de Curitiba e não muito chique na época.

Figura 3. Eloy (Alceu Chichôrro). O Dia, 26 de abril de 1936, n.3566 (Adaptado).

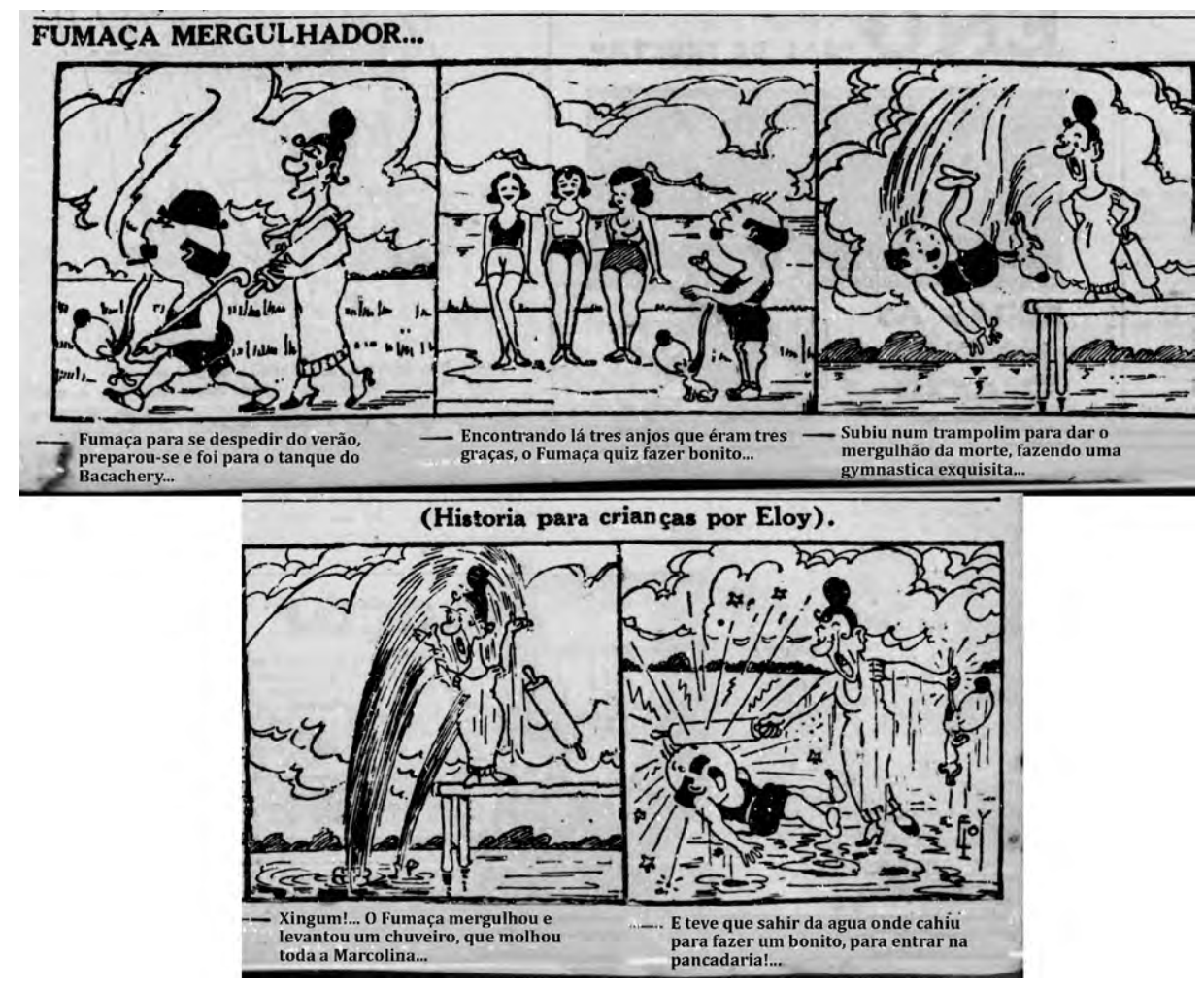

Fonte: Hemeroteca da Biblioteca Nacional. 
No Brasil do início do século XX, o casal Zé Macaco e Faustina, criados por Alfredo Storni ${ }^{9}$ (1881-1966), em 1911, retratava a classe média brasileira ascendente e alienada com o "teatro da modernidade", do progresso e civilização divulgado na Primeira República (Almanaque D’O Tico-Tico, 20o6: 145; Costa \& Schwarcz, 200o). Enquanto Zé Macaco se deslumbrava com as invenções e novidades tecnológicas, Faustina possuía preocupações com as aparências, ambos tendo o dia a dia como pano de fundo. Os personagens denotavam traços afrobrasileiros e eram caracterizados como ignorantes e atrapalhados, fora de moda, com gestos grotescos e atitudes grosseiras. Faustina demonstrava adesão a algumas ideias dos movimentos feministas, como no dia em que tentou participar de uma marcha pela emancipação das mulheres (Figura 4) ${ }^{10}$, agrediu o marido e saiu desfilando, carregando uma bandeira de liberdade, embora gritasse "mancha-paixão" (no lugar de emancipação), ativando o efeito de humor da cena. Um outro momento foi quando, no desejo de seguir a moda das saias calções, vestiu as calças do marido e saiu às ruas, causando tumulto e indignação dos homens da cidade (O Tico-Tico, 1911, n. 288).

9 O gaúcho Alfredo Storni nasceu em Santa Maria, Rio Grande do Sul em 1881. Mudou-se para o Rio de Janeiro em 1907, onde passou a trabalhar como chargista e caricaturista político no O Malho. Mas, foi com o casal Zé Macaco e Faustina que Storni, com sua "aguda veia humorística", ganhou notoriedade ao traduzir os excessos das modas estrangeiras em O Tico-Tico por quase quatro décadas (Lima, 1963: 1231).

10 Provável referência ao movimento sufragista eà fundação do Partido Republicano Feminino em 1910, no Rio de Janeiro, por Leolinda Daltro e outras feministas, entre elas, a escritora Gilka Machado. 
Figura 4. Alfredo Storni. Zé Macaco. OTico-Tico, o7 jun. 1911, n. 296, p. 11.

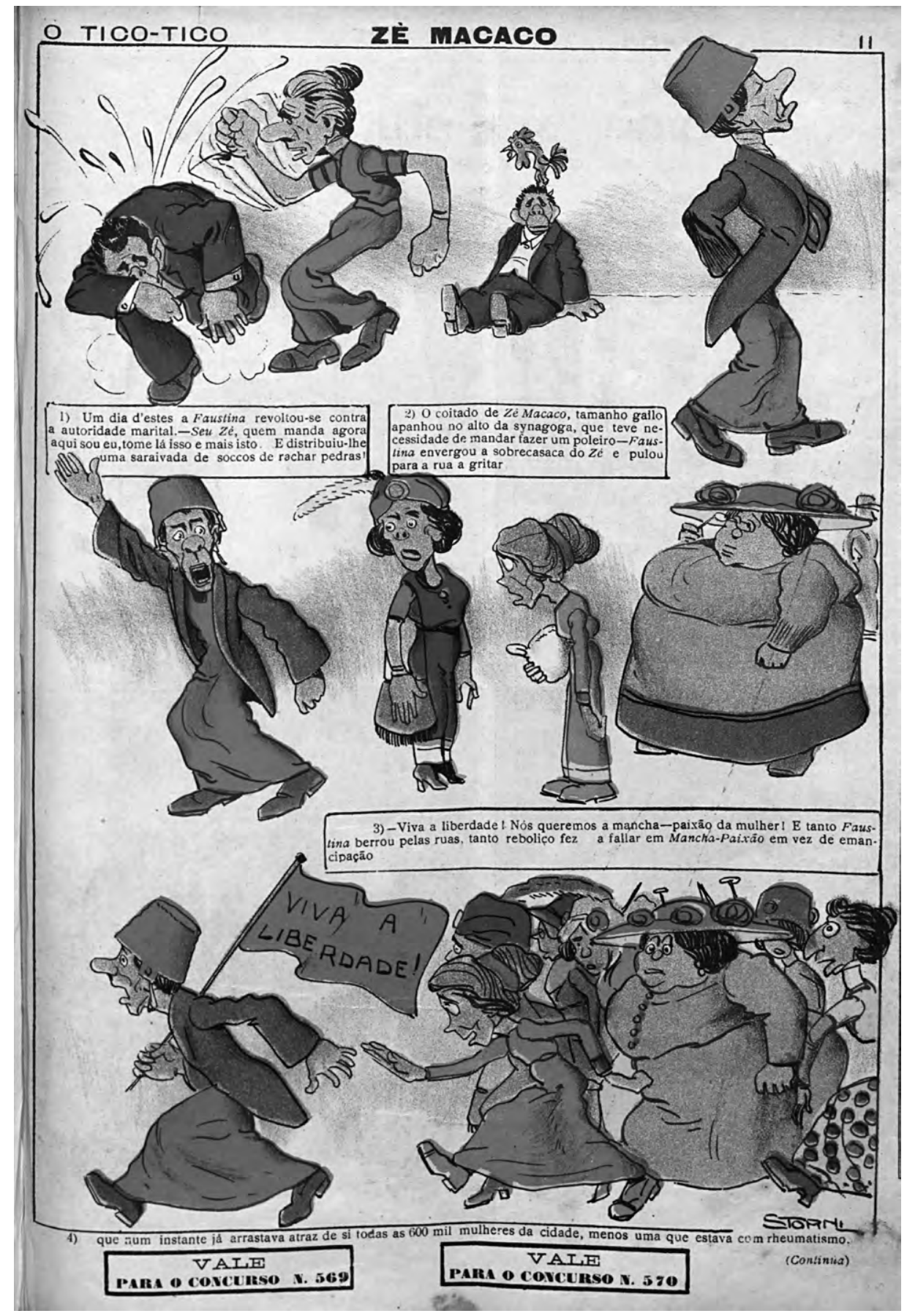

Fonte: Hemeroteca da Biblioteca Nacional

Faustina possui semelhanças físicas com D. Marcolina: ambas são altas, com nariz protuberante, coques como penteado, com valores sociais de feminilidade muito próximos em relação à família, sendo uma das influências de Alceu Chichôrro ao conceber a sua personagem. No entanto, suas personalidades são distintas: Faustina está sempre procurando se encaixar nos padrões de etiqueta das classes médias e altas com sua personalidade forte e gestos pesados, por vezes teatrais, e sem 
sucesso nas suas empreitadas, enquanto para D. Marcolina, mesmo pertencendo às classes médias curitibanas (e frequentemente com empregada em casa ${ }^{11}$ ), demonstra seu autoritarismo sobre Chico Fumaça predominantemente no âmbito privado e, eventualmente, no público. Ambas representavam em seus corpos as marcas das mulheres de meia-idade, com suas feições grosseiras, posturas corporais desajustadas por serem magras demais, pouca vaidade ou, quando presente, esta vaidade se demonstrava pelo excesso, de forma desatualizada.

Nesta mesma linha de autoritarismo e mais além do período temporal considerado, tem-se a Família Burrón, famosa no México pela dinâmica familiar similar. Criada em 1948 por Gabriel Vargas ${ }^{12}$ (1918-2010), a Família Burrón se caracterizou por retratar a família mexicana de classe baixa, ao contrário do casal Pafúncio e Marocas, com sua trama concentrada nos dramas da ascensão social. Sua narrativa acontece na Cidade do México, local de efervescência, com contrastes políticos e sociais, os quais são refletidos em seus personagens, com o "seu estilo de vida, suas possibilidades em um mundo de desenvolvimento de suas redes socioculturais"'3 (Colín, 2010: 74). Para Maurício Colín (2010), Borola Tacuche de Burrón é a mãe e a chefe da família que sintetiza os sentimentos advindos da cidade:

Borola é uma personagem representativa do ator da cidade social que, na contradição do duplo discurso (moralmente falando), encontra uma maneira de sobreviver: é corajosa, determinada, frontal, combativa e aparentemente livre (ou em processo de emancipação); por outro lado, ela é uma dona de casa, dedicada, o eixo emocional de sua família, dependente do amor de Regino, de uma esposa ciumenta, de uma mãe rendida, de uma boa vizinha e, aparentemente, prisioneira de suas paixões e ideais. É machista se é aceitar uma namorada com filhos para Ruperto e é feminista se é uma questão de reclamar da sociedade patriarcal; ela é a irmã do ladrão, ela pede desculpas, ela o ama e ela sofre por ele, mas ela também é um ladrão. Ela é egoísta, gananciosa e enganadora, mas é uma líder nobre que luta pelo bem comum ${ }^{14}$ (Colín, 2010: 76).

11 As edições O Dia, 28 jan. 1936, O Dia, 20 out. 1936, O Dia, 31 out. 1939 e O Dia, 19 jun. 1942 são alguns exemplos com a presença de uma empregada trabalhando para a dupla.

12 Gabriel Bernal Vargas nasceu em Tulancingo, interior do México, em 1918. Sua produção está atrelada à sensibilidade com que apresentou a vida na cidade grande. Dentre as suas principais obras estão a Família Burrón e Los Superlocos, por exemplo (Colín, 2010).

13 "[...] su estilo de vida, sus posibilidades en el mundo y el desarrollo de sus redes socioculturales" (Colín, 2010: 74).

14 "Borola es un personaje representativo del actor social citadino que, em la contradicción del doble discurso (moralmente hablando), encuentra un modo de sobrevivir: es valiente, determinada, frontal, combativa y aparentemente libre (o en proceso de emancipación); por otra parte es ama de casa, devota, eje emocional de su familia, dependiente del amor de Regino, esposa celosa, madre entregada, buena vecina y, aparentemente, prisionera de sus pasiones e ideales. Es machista si se trata de aceptar una novia con hijos para Ruperto y es feminista si se trata de quejarse de la sociedad patriarcal; es la hermana 
Figura 5. Paquito, 26 dez. 1976, capa

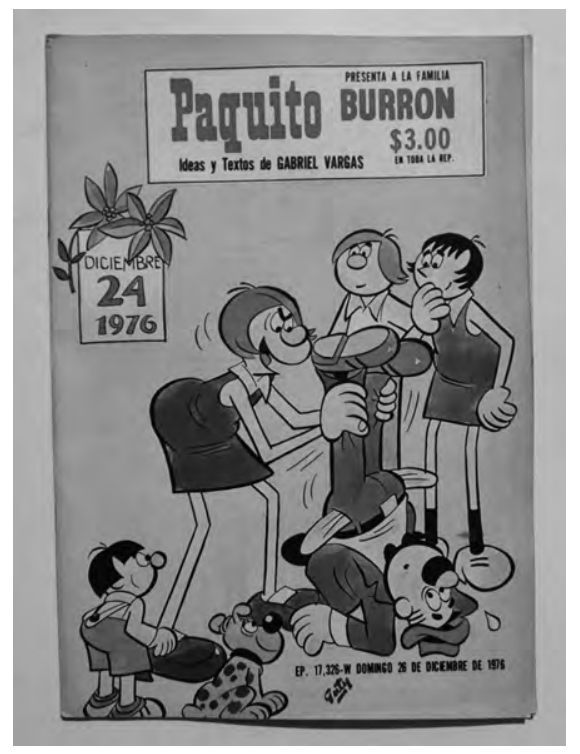

Fonte: https://goo.gl/V4RNeL

Na descrição de Barola por Colín (2010), a ideia de egoísmo e de ganância para tirar a família da pobreza se traduz em atitudes moralmente questionáveis. Uma representação de feminilidade que prioriza a família acima de tudo, dialogando com a dinâmica e os desafios das grandes metrópoles. Estas personagens foram concebidas em meio a um modelo idealizado de família nuclear, com a divisão social dos papéis de homens e mulheres, consolidada na década de 1920, de cunho elitista e disciplinador centrada na figura feminina associada ao lar e à maternidade. Esta deveria ser uma mãe zelosa, modelo de civilidade, aquela que educa para o engrandecimento da nação; cuida do lar e do marido, ao qual deve respeito (Carvalho, 1999). Nos desenhos, Dona Marcolina, apesar de solteira, incorporava os discursos em torno da "família ideal", da moral prescrita pela Igreja e pelos discursos oficiais do Estado.

O que se nota nestas personagens é o sucesso de uma forte reincidência de um estereótipo que pode suscitar vários sentimentos relacionados ao outro que também é representado. As disputas de representações identitárias e de tipos populares precisa ser compreendida no contexto das mudanças de comportamento e de percepção da sociedade, em diálogo com a noção eurocentrista de modernidade do início do século XX. Para Monica Velloso (2011:369), “os estereótipos oferecem elementos cognitivos e identitários capazes de organizar ideias e produzir referenciais de autoconhecimento e de ação para os diferentes grupos sociais". Aqui as disputas residem no campo político e simbólico, com a Primeira República procurando estabelecer uma identidade nacional e "os investimentos de valores e significações emocionais que são construídos na trama da vida cultural e cotidiana” (Velloso, 2011: 369).

A autora assinala a importância e a necessidade de se estudar os estereótipos. Para ela, não se levar a sério e rir de nós mesmos e da nossa história possibilita

del ladrón, lo disculpa, lo quiere y sufre por él, pero es también ladrona. Es egoísta, avara y tramposa, mas es líder noble que lucha por el bien común” (Colín, 2010: 76). 
refletir sobre a nossa realidade. "A ironia é qualidade essencial para refletir sobre a alteridade" (Velloso, 2011: 383), a heterogeneidade cultural da identidade brasileira. Os estereótipos possuem inúmeras agências quando dentro de um mesmo universo cultural, provocam tensionamentos, apontam contradições, projetam olhares nem sempre tão positivos, por vezes arraigados de pré-conceitos e simplificações pejorativas (Velloso, 2011).

Pensando sobre as relações entre os estereótipos do português pelos brasileiros e vice-versa, Isabel Lustosa e Robertha Triches (2011) ressaltam que o riso se extrai dessa

[...] seleção de aspectos do outro que distinguem dos nossos aspectos que nos parecem estranhos, curiosos, ou errados, ou seja, uma valorização do nós em detrimento do eles, compreendendo identidade e alteridade, diversidade e desigualdade. O outro escolhido tem que nos ser familiar, tem que ser alguém próximo, mas ao mesmo tempo diferente. [...] (Lustosa \& Triches, 2011: 266).

Para ambas as pesquisadoras, a alteridade é um elemento-chave para entender o estereótipo. É a partir dela que se constroem as visões sobre o outro, seja rindo de si ou reforçando preconceitos de/pelo outro.

As situações construídas por Alceu Chichôrro são, em sua maioria, fatos ambíguos, em que a malandragem, as atitudes "traquinas" podem ser vistas como brincadeiras inocentes, como atos fortuitos. As aventuras, "escapadelas" de Chico Fumaça parecem verdadeiros atos heroicos, troféus/recompensas na vida de um homem, apesar das repreensões ao final. Já para D. Marcolina resta a monotonia dos serviços da casa, da administração do lar, sem nenhum traço dinâmico de ação, exceto quando usa a vassoura, o rolo de macarrão, outros utensílios domésticos e até facas para punir o companheiro. No caso da Figura 6, a ambiguidade se constrói no entendimento equivocado de $\mathrm{D}$. Marcolina sobre a música tocada no rádio comprado por Chico Fumaça, gerando uma reação violenta, como uma mãe punindo um filho. Porém, as motivações de Fumaça quase sempre estão relacionadas ao tipo conquistador. 
Figura 6. Eloy (Alceu Chichorro), O Dia, o9 jun. 1935, capa (Adaptado).

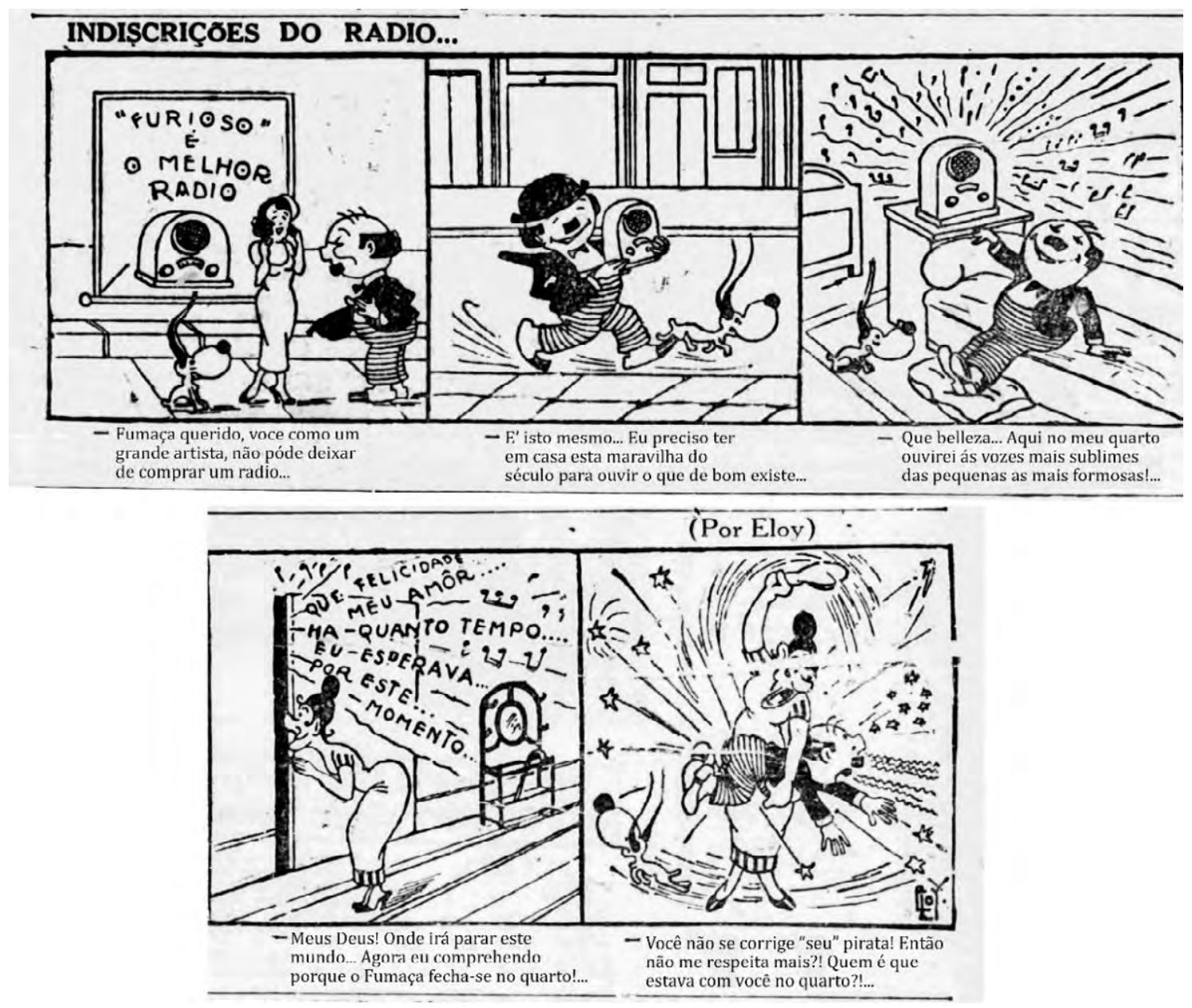

Fonte: Hemeroteca da Biblioteca Nacional

A figura de D. Marcolina contrasta física e socialmente com a garota, não identificada, que convence o calunga a adquirir um rádio "Furioso", possivelmente acreditando no talento artístico que ele diz possuir. É perceptível o contraste entre a jovem moderna, por dentro das novidades técnicas, como o rádio, e a mulher pertencente a uma geração anterior, desatualizada em relação aos lançamentos musicais e aos novos aparelhos tecnológicos. A valorização da juventude é uma tônica que se intensifica no início do século XX, no qual o ver e o ser visto entre as classes médias e altas começa a se tornar comum no espaço público. A “ideologia da juventude” envolveu novas mídias e tecnologias, como a indústria de cosméticos, advento de novos artefatos e a moda, "elementos fundamentais desse movimento coletivo de proscrição do velho" (Schpun, 1999: 32). A feiura e a velhice eram estigmatizadas, marginalizadas e satirizadas. O efeito cômico se produz pelo gestual indelicado, pelos rompantes agressivos, tidos como o avesso da representação ideal de feminilidade. Chichôrro constrói Marcolina como o exemplo de insensatez e símbolo das opressões e limitações da vida na sociedade, da vida em comum. 


\section{CONSIDERAÇÕES}

Tipos femininos como D. Marcolina representam um conjunto de normas e práticas atreladas à dinâmica da modernização da sociedade e aos novos modos de ver e sentir o crescimento das cidades. São representações sociais que estabeleceram fácil identificação com o público leitor e tanto promovem questionamentos acerca dos modelos sociais de gênero, quanto os reforçam. As family strips como um modelo plural de construção de personagens de quadrinhos em diferentes contextos históricos e culturais, promoveram rupturas com determinados conceitos de família quanto reiteraram posições sociais dos sujeitos por meio da inversão satírica de gênero.

É possível visualizar vários processos de ressignificação de estilos de vida ditos "ideais", sempre em tensionamentos com modos de viver que vão "contra” as normas estabelecidas, insinuando as desigualdades presentes nas relações sociais. Para D. Marcolina, o casamento e a maternidade possuíam uma sacralidade, dialogando com o discurso vigente da Igreja, do Estado e do discurso médico, na qual ela adere como meio de sobrevivência frente a uma lógica social machista conservadora. Suas crenças e comportamentos são tidos como pontos positivos em relação ao discurso vigente de moral do período.

A linha entre a figura materna e a companheira se mostra muito fluida na relação entre D. Marcolina e Chico Fumaça. Esta oscilação entre representações permite a Alceu Chichôrro, em princípio, explorar com maior complexidade as temáticas cotidianas em seus trabalhos e situar Marcolina como uma personagem auxiliar em relação a um personagem principal masculino, idealizada por um homem.

É possível indagar como o autoritarismo de D. Marcolina ou das outras personagens apresentadas questiona ou reforça as posições de sujeitos, as assimetrias de poder entre homens e mulheres. Marcela Gené (2012) considera que o contraste visual entre a composição física dos personagens revela as disputas de poder, e é a inversão que gera o efeito cômico. Ou seja, uma mulher que domina a situação, que controla, reprime e manda em casa, torna-se hilária por destoar das práticas sociais esperadas. Nas histórias abordadas, a figura feminina é composta de forma alta e magra, em oposição à figura masculina baixa e corpulenta. A inversão visual dos papéis de gênero promove o riso, porém, não ressignifica as relações sociais. Salvo algumas eventuais ameaças em público (em especial no carnaval), D. Marcolina exerce seu poder repreensivo sobre o sobrinho no espaço privado, no lar, no recôndito das relações conjugais/parentais.

As outras figuras femininas que interagem com Chico Fumaça, em geral, também possuem estatura superior à dele, e parece reiterar o papel da figura feminina como algo simbolicamente dominante na vida de Chico Fumaça, tanto dentro quanto fora do lar. Uma dominância que se traduz tanto em conquistas amorosas quanto nas pancadas e vigilâncias de D. Marcolina.

Itens como o pau de macarrão, a vassoura ou o tamanco são artefatos ressignificados por D. Marcolina, bem como para outras figuras maternas nas 
family strips. Utilizadas como armas de violência, elas exteriorizam a intenção de condicionar e disciplinar a figura masculina. Ao deixar claro seu ponto de vista por meio das tamancadas, também se verifica uma postura de manutenção das relações como meio de sobrevivência por parte da D. Marcolina. Uma busca pela conservação do status quo manifestada a partir de usos inusitados dos objetos domésticos para exercer algum controle em seu universo cotidiano.

Os artefatos, as materialidades presentes na obra de Chichôrro mostram as influências da modernização do país, das transformações na paisagem urbana, da indústria cultural. O rádio é apontado como novidade e fonte de prazer, bem como elemento que pode modificar comportamentos, até mesmo desviar condutas, aos ouvidos moralistas de Dona Marcolina. O uso dos novos aparelhos e das informações atualizadas está, quase sempre, associado a uma questão geracional. A era Vargas, conhecida como a era do rádio, passa a ser problematizada pelo ritmo acelerado das transformações do país, das novas relações de trabalho, das novas formas de comportamento das cidades e das pessoas (Sevcenko, 1998). O ideal de progresso e modernização é confrontado com os hábitos conservadores e desconfiados da capital paranaense.

Faustina, Marocas, Dona Marcolina e Barola, entre outras, formam um time de megeras que não se deixaram domar, criando estratégias bastante singulares para se livrarem das armadilhas de novos padrões de beleza e de um processo de modernização da sociedade que insistia na manutenção dos valores tradicionais da família. Essas personagens criadas por homens desenhistas demonstram a eficácia em desqualificar e ridicularizar determinadas figuras femininas, caracterizandoas como limitadas, desconectadas do mundo da ciência e da tecnologia, presas ao ambiente doméstico e às convenções sociais. Por outro lado, se a inversão dos papéis de gênero traz o riso nestas produções, também descortinam estereótipos masculinos e um certo receio das mudanças sociais e dos espaços que estavam sendo conquistados e reivindicados pelas mulheres.

\section{REFERÊNCIAS}

ALMANAQUE D’O TICO-TICO (2006). Rio de Janeiro: Edições Consultor.

BAHLS, Aparecida Vaz da Silva; BUSO, Mariane Cristina (2009). "A sociedade sob o olhar de Chichorro". In: Fatos da Atualidade: Charges e Caricaturas em Curitiba de 1900-1950. Curitiba: Fundação Cultural de Curitiba, v. 33, n. 142.

BOIA, Wilson. Alceu Chichôrro (1998). Curitiba. Secretaria de Estado da Cultura.

BOIA, Wilson. Alceu Chichôrro: Charges (1994). Curitiba: Secretaria de Estado da Cultura. 
CARVALHO, Marilia Pinto de (1999). No coração da sala de aula: gênero e trabalho docente nas séries iniciais. São Paulo: Xamã, p. 51-97.

CHARTIER, Roger (1988). A História Cultural: entre práticas e representações, Lisboa: DIFEL, p. 07-67.

COLÍN, Mauricio del Olmo (2010). "A la muerte de Gabriel Vargas”. In: La Colmena, n. 67-68, p. 72-78, jul/dec.

COSTA, Ângela Marques; SCHWARCZ, Lilia Moritz (2000). 1890-1914: no tempo das certezas. São Paulo: Cia. das Letras.

GENÉ, Marcela (2012). “'Sisebutas' en Buenos Aires. Family strips de los años veinte”. In: Antíteses, Londrina, v. 5, n. 9, jan./jul, p. 201-224.

HALL, Stuart (2016). Cultura e representação. Rio de Janeiro: Ed. PUC-Rio: Apicuri.

HOUAISS, Antônio. Dicionário Houaiss eletrônico da Língua Portuguesa (2009). Rio de Janeiro: Objetiva.

LAMBIEK Comiclopedia (2014). George McManus. Disponível em: <https://lambiek. net/artists/m/mcmanus.htm>. Acesso em: 04 de set. 2018.

LUSTOSA, Isabel; TRICHES, Robertha. "O português da anedota”. In: LUSTOSA, Isabel (Org.) (2011). Imprensa, humor e caricatura: a questão dos estereótipos. Belo Horizonte: UFMG, p. 251-269.

LIMA, Herman. História da caricatura no Brasil, v. 3. Rio de Janeiro: José Olympio, 1963.

MALUF, Marina; MOTT, Maria Lúcia. "Recônditos do Mundo Feminino". In: SEVCENKO, Nicolau. (Org.) (1998). História da Vida Privada no Brasil República, v. 3. São Paulo: Companhia das Letras, p. 367-421.

OLIVEIRA, Selma Regina Nunes. Mulher ao quadrado: as representações femininas nos quadrinhos norte-americanos: permanências e ressonâncias (1895-1990) (2007). Brasília: Editora Universidade de Brasília: Finatec.

GOIDANICH, Hiron Cardoso; KLEINERT, André. (2011) Enciclopédia dos Quadrinhos. Porto Alegre, RS: L\&PM.

SCHPUN, Mônica Raisa (1999). Beleza em jogo: cultura física e comportamento em São Paulo nos anos 20. São Paulo: Senac. 
SEVCENKO, Nicolau. "A capital irradiante: técnica, ritmos e ritos do Rio." In: SEVCENKO, Nicolau (Org.) (1998). História da Vida Privada no Brasil República, v. 3. São Paulo: Companhia das Letras, p. 514-619.

SWAIN, Tânia Navaro (200o). "A invenção do corpo feminino ou 'a hora e a vez do nomadismo identitário?"'. In: Textos de História, Brasília, v. 8, n. 1/2, p. 47-84.

SWAIN, Tânia Navaro (2001). "Feminismo e representações sociais: a invenção das mulheres nas revistas 'femininas”. In: História: Questões $\mathcal{E}$ Debates, Curitiba, n. 34, p. 11-44.

O TICO-TICO (1911). Hemeroteca da Biblioteca Nacional. Disponível em: <http:// bndigital.bn.br/acervo-digital/almanaque-tico-tico/o59730>. Acesso em: 13 set. 2018.

O DIA (1935, 1936, 1942). Hemeroteca da Biblioteca Nacional. Disponível em: <http:// bndigital.bn.gov.br/hemeroteca-digital/>. Acesso em: 13 set. 2018.

VELLOSO, Mônica Pimenta. "A mulata, o papagaio e a francesa: o jogo dos estereótipos culturais". In: LUSTOSA, Isabel (Org.) (2011). Imprensa, humor e caricatura: a questão dos estereótipos. Belo Horizonte: UFMG, p. 365-387.

VERGUEIRO, Waldomiro. "As histórias em quadrinhos e seus gêneros IV: os quadrinhos em ambiente familiar”. In: InfoHome, Outubro (2003). Não está no gibi. Disponível em: <http://www.ofaj.com.br/colunas_conteudo.php?cod=145>. Acesso em: 26 jul. 2018.

Recebido: 13.09.2018

Aceito: 15.10.2018 